OPEN ACCESS

Edited by:

Esther M. Lafuente, Complutense University of Madrid,

Spain

Reviewed by:

Amiram Ariel,

University of Haifa, Israel

Jeffrey Louis Curtis,

University of Michigan Medical

School, United States

*Correspondence:

loannis Kourtzelis

ioannis.kourtzelis@york.ac.uk

Specialty section:

This article was submitted to

Molecular Innate Immunity,

a section of the journal

Frontiers in Immunology

Received: 12 January 2020

Accepted: 11 March 2020

Published: 31 March 2020

Citation:

Kourtzelis I, Hajishengallis G and Chavakis T (2020) Phagocytosis of Apoptotic Cells in Resolution

of Inflammation.

Front. Immunol. 11:553.

doi: 10.3389/fimmu.2020.00553

\section{Phagocytosis of Apoptotic Cells in Resolution of Inflammation}

\author{
loannis Kourtzelis ${ }^{1,2 *}$, George Hajishengallis ${ }^{3}$ and Triantafyllos Chavakis ${ }^{1,4}$ \\ ${ }^{1}$ Institute for Clinical Chemistry and Laboratory Medicine, University Hospital and Faculty of Medicine, Technische Universität \\ Dresden, Dresden, Germany, ${ }^{2}$ Hull York Medical School, York Biomedical Research Institute, University of York, York, \\ United Kingdom, ${ }^{3}$ Laboratory of Innate Immunity and Inflammation, Penn Dental Medicine, Department of Basic \\ and Translational Sciences, University of Pennsylvania, Philadelphia, PA, United States, ${ }^{4}$ Centre for Cardiovascular Science, \\ Queen's Medical Research Institute, University of Edinburgh, Edinburgh, United Kingdom
}

Efficient inflammation resolution is important not only for the termination of the inflammatory response but also for the restoration of tissue integrity. An integral process to resolution of inflammation is the phagocytosis of dying cells by macrophages, known as efferocytosis. This function is mediated by a complex and well-orchestrated network of interactions amongst specialized phagocytic receptors, bridging molecules, as well as "find-me" and "eat-me" signals. Efferocytosis serves not only as a waste disposal mechanism (clearance of the apoptotic cells) but also promotes a pro-resolving phenotype in efferocytic macrophages and thereby termination of inflammation. Alterations in cellular metabolism are critical for shaping the phenotype and function of efferocytic macrophages, thus, representing an important determinant of macrophage plasticity. Impaired efferocytosis can result in inflammation-associated pathologies or autoimmunity. The present mini review summarizes current knowledge regarding the mechanisms regulating macrophage efferocytosis during clearance of inflammation.

Keywords: phagocytosis, efferocytosis, DEL-1, immunometabolism, inflammation resolution, integrins

\section{INTRODUCTION}

Specific recognition and engulfment of "foreign" material or pathogens by host cells, designated as phagocytosis, is an essential process modulating the immune response and tissue homeostasis $(1,2)$. Besides phagocytosis of opsonized pathogens by phagocytes during an infection, host cells undergoing apoptosis are also cleared by macrophages; the specific phagocytosis of dying cells by macrophages is designated efferocytosis (3). The specific pathways for phagocytosis of different types of cargo point to the versatility of the phagocytic machinery $(1,2)$.

A central player in sterile inflammation or inflammation associated with infection are neutrophils recruited to the inflamed site $(4,5)$. Recruited neutrophils phagocytose and kill pathogens, produce reactive oxygen species (ROS) and pro-inflammatory factors, such as cytokines, and can either release neutrophil extracellular traps (NETs) or undergo apoptosis (46). Efferocytosis is therefore of great importance in the regulation of neutrophilic inflammation (3, $7-10$ ). Effective removal of dying neutrophils promotes not only inflammation resolution but also contributes to restoration of tissue and organ homeostasis (3). A complex network of interactions between receptors mediating phagocytosis, bridging molecules, "find-me" and "eat-me" signals, such as phosphatidylserine (PS), which is presented on the outer part of the membrane of cells undergoing apoptosis, contributes to the formation of phagocytic synapse (Figure 1) and the operation of the efferocytic machinery $(7,8,11)$. As resolution of inflammation occurs, efferocytic macrophages acquire a resolving phenotype producing factors that dampen inflammation and promote restoration of tissue integrity, such as IL-10 or transforming growth factor $\beta$ (TGF $\beta$ ) (3), 

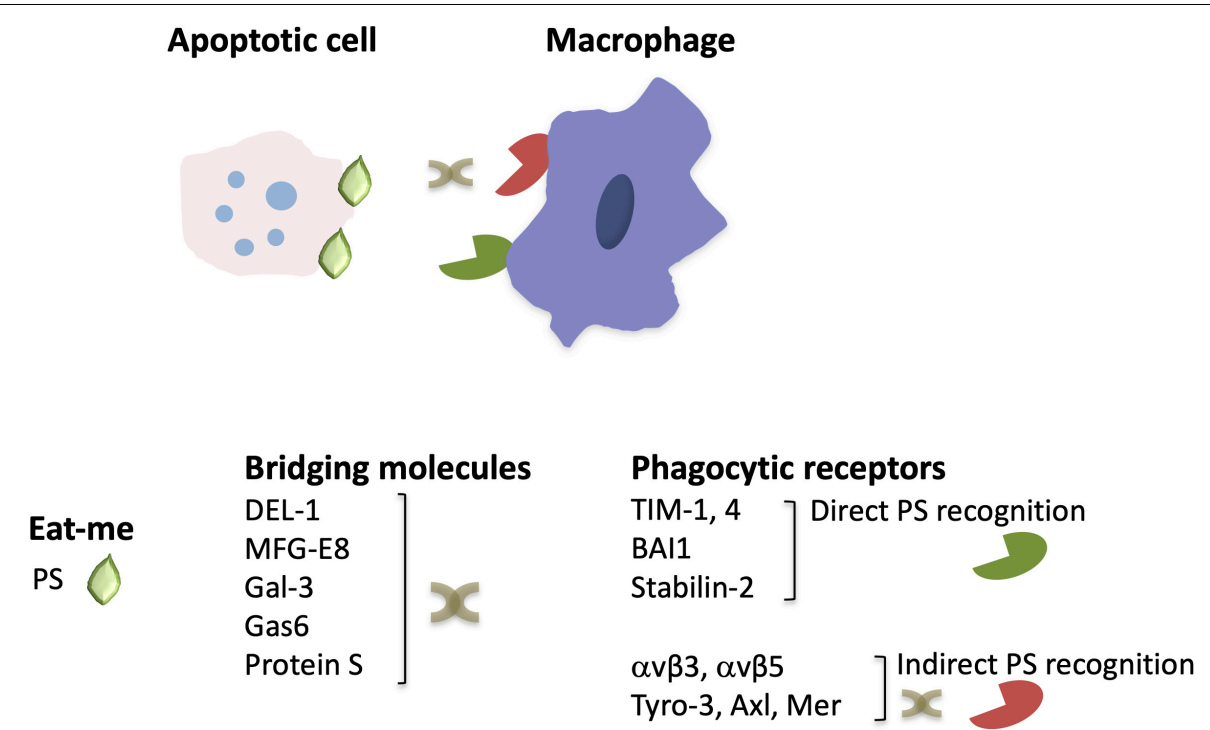

FIGURE 1 | The structure of engulfment synapse. During efferocytosis, the clearance of apoptotic cells by macrophages is orchestrated by the recognition of the major "eat-me" signal PS, either directly by PS receptors or via bridging molecules that mediate binding of PS to phagocytic receptors. Depicted are a few examples of phagocytic receptors and bridging molecules that are described in the text (see text for primary references).

as well as specialized pro-resolving lipid mediators (SPM), such as resolvins, lipoxins, and maresins $(9,12)$. SPM synthesis can further promote efferocytosis, thereby further potentiating inflammation resolution $(9,12)$. Defective removal of apoptotic cells resulting from impaired efferocytosis can lead to chronicity of inflammation and development of inflammatory disorders, such as atherosclerosis and autoimmune diseases $(9,13-15)$.

Emerging evidence suggests that macrophage function is regulated by alterations in their cellular metabolism in response to environmental cues within the inflammatory milieu (16). For instance, specific metabolic components may promote or suppress inflammatory responses in macrophages (16). Importantly, efferocytosis also promotes immunometabolic reprograming in macrophages (17) (Figure 2). For example, digestion of the engulfed apoptotic cargo through phagolysosomal activity results in a load of lipid components derived from the apoptotic cell membranes that is linked to enhanced fatty acid oxidation and regulates macrophage function (17-19). The mechanisms underlying apoptotic cell removal by macrophages as well as the immunometabolic alterations in efferocytic macrophages during inflammation resolution is the focus of the present review.

\section{MOLECULAR CROSS-TALK BETWEEN APOPTOTIC CELLS AND MACROPHAGES DURING EFFEROCYTOSIS}

The engulfment of dying cells by efferocytic macrophages requires the recognition of the former by the latter and the formation of the engulfment synapse, which is regulated by a network of "find-me", "eat-me" and bridging molecules, "don't eat-me" signals and specialized phagocytic receptors (11) (Figure 1). Neutrophils undergoing apoptosis during an inflammatory response, secrete molecules serving as "findme" signals that can attract phagocytes to eliminate apoptotic cell corpses $(20,21)$. These include the nucleotides adenosine triphosphate (ATP) and uridine triphosphate (UTP), which are recognized by the macrophage purinergic receptor P2Y2 (22), or the lipids lysophosphatidylcholine (LPC) (23) and sphingosine1-phosphate (24), which bind to macrophage G-proteincoupled receptors G2A and S1P1-5, respectively. Furthermore, recognition of dying cells by macrophages may be facilitated by the interaction of intercellular adhesion molecule 3 (ICAM3 or CD50) on the former with CD14 on macrophages (25) as well as by the thrombospondin (TSP1)-CD36 interaction (26). Moreover, the specific recognition of apoptotic cells is ensured by the presence of "eat-me" signals. PS is the most well characterized "eat-me" signal (Figure 1). During apoptosis, this phospholipid is found on the outer part of the membrane and binds directly or indirectly, via bridging molecules (opsonins), to phagocytic receptors $(27,28)$. Calreticulin (Crt) is a membrane-associated protein that functions as an "eat-me" signal' on the surface of dying cells and is recognized by the LDL-receptor-related protein 1 (LRP1 or CD91) on phagocytes (29). The long pentraxin PTX3 may also act as an "eat-me" signal to facilitate the capture of dying neutrophils by macrophages (30).

As alluded to above, bridging molecules are often key to efficient interactions between apoptotic neutrophils and macrophages (11). Milk fat globule-EGF factor 8 protein (MFGE8 or lactadherin) promotes efferocytosis by binding to PS on apoptotic cells and to macrophage phagocytic integrin receptors $\alpha v \beta 3$ and $\alpha v \beta 5(31,32)$. MFG-E8 shares homology with developmental endothelial locus-1 (DEL-1). Besides the established anti-inflammatory role of DEL-1 as inhibitor of $\beta 2$ 


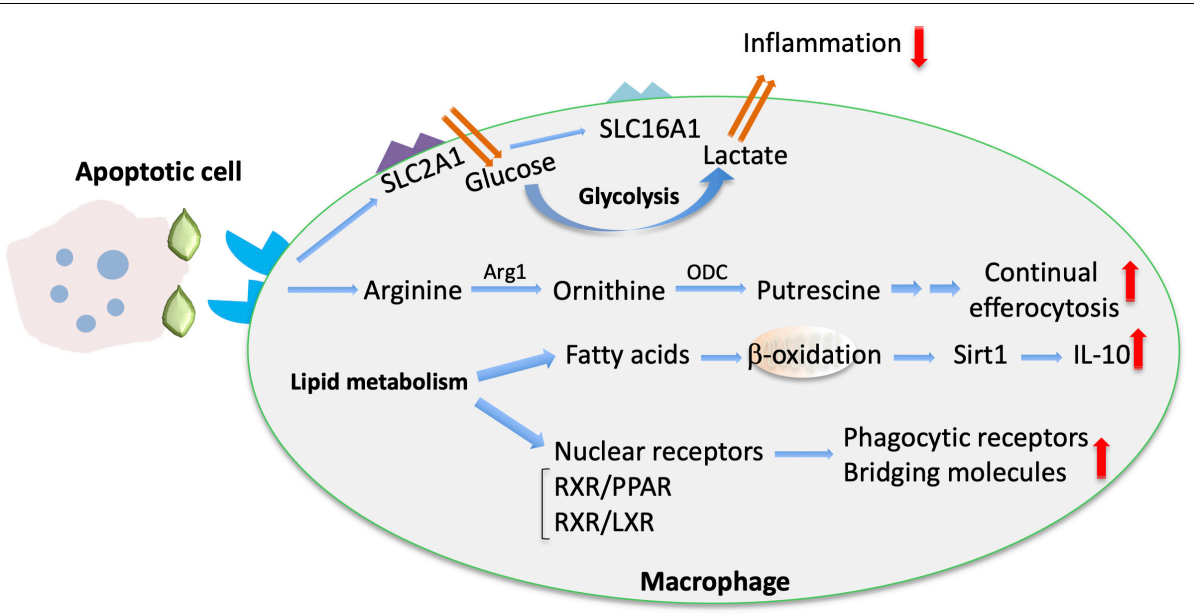

FIGURE 2 | Metabolic cues implicated in macrophage efferocytosis. Upon efferocytosis, increased glucose uptake via upregulated SLC2A1 and enhanced glycolysis are linked with enhanced lactate release via SLC16A (102). The metabolism of arginine and ornithine to putrescine is involved in promoting continual efferocytosis (105). In addition, enhanced lipid metabolism upon efferocytosis is associated with fatty acid oxidation and Sirtuin 1 (Sirt1)-dependent upregulation of IL-10 (18). Moreover, activation of lipid transcription factors (e.g., the LXR/RXR or PPAR/RXR heterodimers) promotes the upregulation of bridging molecules and phagocytic receptors and the resolving macrophage phenotype (107).

integrin-dependent leukocyte recruitment and IL-17-mediated inflammation $(8,33-38)$ and its role as a regulator of bone marrow myelopoiesis $(39,40)$, secreted DEL-1 promotes engulfment of apoptotic cells and inflammation resolution (41). In particular, DEL-1 functions as a molecular bridge that binds concomitantly to PS on the apoptotic neutrophil surface via its C-terminal discoidin I-like domains and to $\alpha v \beta 3$ integrin [also known as vitronectin receptor (42)] on macrophages via its N-terminal RGD motif within the second EGF-like domain $(41,43)$. Importantly, the compartmentalized localization of DEL-1 differentially regulates the inflammatory response. Specifically, the endothelial cell-derived molecule promotes anti-inflammatory activity by blocking $\beta 2$ integrindependent leukocyte recruitment, whereas DEL-1 derived from macrophages promotes efferocytosis-dependent resolution of inflammation $(33,41)$ (Figure 1). Other molecules that act as a molecular bridge to facilitate interactions between apoptotic cargo and phagocytes include annexin A1 or lipocortin-1 (44), $\beta 2$-glycoprotein-I ( $\beta 2$-GPI) (45), and galectin-3 (Gal-3) (46). Moreover, the bridging molecules Growth arrest-specific factor 6 (Gas6) and protein S have been implicated in PS-mediated apoptotic cell clearance $(47,48)$ via interacting with the receptor tyrosine kinases Tyro-3, Axl and Mer (TAM) (49-52) (Figure 1).

Phagocytic receptors on macrophages involved in the regulation of efferocytosis include also the PS receptors of the T-cell membrane protein (Tim) family, such as TIM-1 and TIM-4 (53, 54). The brain angiogenesis inhibitor 1 (BAI1) (55) and stabilin-2 (56) also serve as PS receptors (Figure 1). Additionally, CD14, the scavenger receptor CD36, and the integrin CD11b/CD18 ( $\alpha \mathrm{M} \beta 2$ ) (besides the integrins $\alpha v \beta 5$ and $\alpha v \beta 3$ that were mentioned above) are implicated as efferocytosis receptors $(8,11,26,42,57,58)$.

The presence of "don't eat-me" signals further adds to the complexity of the regulation of apoptotic cell clearance. Specifically, surface expression of CD47 (also named integrin-associated protein) prevents phagocytosis by macrophages $(59,60)$. Binding of CD47 to the macrophage signal regulatory protein alpha $(\operatorname{SIRP} \alpha)$ modulates rearrangement of actin cytoskeleton, thereby downregulating phagocytosis (59, 60). However, apoptotic cells have decreased levels of CD47 that allows their clearance by macrophages (59-61). Platelet and endothelial cell adhesion molecule 1 (PECAM-1, CD31) also exerts a "don't eat-me" function. In this regard, homotypic CD31 interaction between non-apoptotic neutrophils and macrophages may prevent phagocytic clearance (62). Furthermore, CD24 (63) and the complement receptor CD46 (64) have been described as repulsive signals that interfere with efferocytosis. Decreased presence or alterations in the distribution of "don't eat-me" signals have been associated with enhanced efferocytic activity $(65,66)$.

Efficient efferocytosis is critical for shaping the pro-resolving phenotype in macrophages that includes production of immunomodulators, which in turn further enhance resolution of inflammation (67-71). For instance, production of TGF $\beta$ by efferocytic macrophages is a major orchestrator of inflammation resolution. Indeed, upregulation of TGF $\beta$ owing to efferocytosis promotes downregulation of the proinflammatory mediators TNF, IL-1 $\beta$ and IL-8. Consistently, antibody-mediated inhibition of TGF $\beta$ restored expression of inflammatory mediators. Along the same line, administration of apoptotic cells in vivo models of inflammation triggers resolution of inflammation in a manner dependent on TGF $\beta$ upregulation $(72,73)$. Additionally, interleukin 13 derived from regulatory $\mathrm{T}$ cells acts on macrophages and promotes production of IL-10, which in turn enhances efferocytosis via activation of Racl GTPase and thereby inflammation resolution in atherosclerosis (74). Besides the upregulation of immune-modulating factors, such as TGF $\beta$ or IL-10, 
the direct inhibition of pro-inflammatory cytokines further contributes to inflammation resolution. As an exemplar, formation of NETs that aggregate at the inflamed site leads to protease-dependent degradation of inflammatory cytokines and chemokines, thereby promoting resolution of acute neutrophilic inflammation (75).

The phenotype of efferocytic macrophages is additionally controlled by the enzyme 12/15 lipoxygenase (12/15-LO) that oxidizes polyunsaturated fatty acids and generates bioactive lipid metabolites leading to the biosynthesis of pro-resolving lipid mediators $(9,76)$. Specifically, apoptotic cell engulfment can be performed by resident or monocyte-derived resolution phase macrophages expressing 12/15-LO (77-80). Apoptotic cell engulfment further promotes the expression of this enzyme (81). Moreover, 12/15-LO has been implicated to function in preventing induction of autoimmunity (77).

Plasminogen and its cleavage product plasmin not only regulate the initiation but also the resolution phase of inflammation. Treatment of mice with plasminogen/plasmin resulted in recruitment of pro-resolving macrophages and in upregulation of TGF $\beta$. Administration of plasminogen/plasmin at the peak of inflammation was associated with increased neutrophil apoptosis and efferocytosis; the pro-resolving effect of plasminogen was mediated by annexin A1 (82). In accordance, impaired efferocytosis accompanied by decreased levels of annexin A1 was observed in mice deficient in plasminogen or its receptor (83). Besides being involved in pro-resolving actions of plasminogen, annexin A1 plays a broader role in inflammation resolution $(84,85)$. Annexin A1 levels are increased in the resolution phase of monosodium urate crystal-induced arthritis, a model of gout. Pharmacologic or genetic inactivation of annexin A1 resulted in insufficient resolution of gout-related inflammation in mice (86). In addition, treatment of mice with annexin A1 resulted in upregulation of IL-10 and downregulation of proinflammatory mediators, while, consistently, inhibition of annexin A1 abrogated inflammation resolution induced by glucocorticoids $(87,88)$.

Moreover, IFN- $\beta$ from macrophages was recently identified as a factor promoting resolution of inflammation. IFN- $\beta$ levels were higher in the resolution phase of pneumonia and peritoneal inflammation. Activation of IFN- $\beta$ signaling via STAT3 enhances apoptosis of neutrophils and their subsequent efferocytic clearance, resulting in a pro-resolving reprograming of macrophages (79).

\section{METABOLIC MODULATION OF MACROPHAGE FUNCTION IN THE CONTEXT OF EFFEROCYTOSIS}

The impact of cellular metabolism on macrophage function and plasticity has gained much attention recently (16, 89-91). Metabolic pathways, such as glycolysis, tricarboxylic acid (TCA) cycle, pentose phosphate pathway and fatty acid oxidation, regulate macrophage phenotype in the context of inflammatory responses (91). For instance, increased glycolytic flux has been linked to pro-inflammatory M1-like activation of macrophages, whereas oxidative phosphorylation is associated with antiinflammatory macrophage polarization (92).

Moreover, macrophage tissue specificity may be associated with differential metabolic activity. For example, resident peritoneal macrophage survival depends on the transcription factor GATA6 that is regulated by the vitamin A metabolite retinoic acid $(93,94)$, while the nuclear receptor liver $\times$ receptor (LXR) alpha that is activated by lipids regulates differentiation of marginal zone splenic macrophages (95). It is now established that tissue-specific resident macrophages have distinct transcriptomic profiles and phenotypes depending on the particular microenvironment $(96,97)$. Importantly, in this regard, the manner by which efferocytosis is regulated in resident macrophages may be dictated by the tissue microenvironment. Indeed, parabiosis-based experiments have revealed substantial heterogeneity in the utilization of bridging molecules, efferocytic receptors and transcription factors by macrophages from different tissues. For instance, the mannose receptor CD206 is upregulated in phagocytic macrophages in bone marrow and intestine but not in the spleen (98). Moreover, the profile of upregulated anti-inflammatory mediators by efferocytic macrophages is tissue-specific (98).

Regulation of macrophage metabolic activity in the context of efferocytosis (Figure 2) is of major importance for the outcome of inflammation resolution and tissue repair (99). Following engulfment, macrophages degrade the apoptotic material through phagolysosomal activity $(100,101)$, resulting in substantial metabolic load and influence on macrophage metabolism (17).

Aerobic glycolysis was recently implicated in regulation of efferocytosis and shaping an anti-inflammatory environment by efferocytic macrophages (102). Specifically, transcriptomic analysis of macrophages engaging in active phagocytosis of apoptotic cells revealed an upregulation of several members of the solute carrier (SLC) membrane transport protein family, including the glucose transporter protein type 1 (GLUT1; encoded by the gene Slc2a1) and monocarboxylate transporter 1 (encoded by Slc16a1) promoting lactate release. Enhanced glycolysis in efferocytic macrophages promoted actin polymerization and continued uptake of apoptotic cells. On the other hand, lactate from efferocytic macrophages contributed to establishment of an anti-inflammatory phenotype of the surrounding tissue (102) (Figure 2). Consistently, knockdown of Slc16a1 in the setting of efferocytosis resulted in reduced mRNA expression of factors linked to the resolving macrophage phenotype and resolution of inflammation, such as $\mathrm{Tg} f b 1$ and Il10 (102). Furthermore, specific deletion of GLUT1 in myeloid cells was associated with defective phagocytic ability of macrophages and with development of unstable lesions in a model of atherosclerosis (103). Moreover, deficiency of the glycolytic enzyme 6-phosphofructose-2-kinase and fructose2,6-bisphosphatase (PFKFB3) in macrophages led to reduced efferocytosis capacity, thus further supporting a role for glycolysis in apoptotic cell clearance (104).

Metabolites derived from engulfed apoptotic cells serve to fine-tune the process of efferocytosis and resolution of inflammation. Apoptotic cells are a source of the amino acids 
arginine and ornithine that are metabolized in macrophages to putrescine. This metabolic process enables continual rounds of efferocytosis (Figure 2). Putrescine enhances, via the RNA-binding protein $\mathrm{HuR}$, the mRNA stabilization of the GTP-exchange factor $\mathrm{Dbl}$. Dbl in turn activates the GTPase Rac1, resulting in changes in the actin cytoskeleton that facilitate further apoptotic cell engulfment. Exogenous administration of putrescine increases inflammation resolution in the context of atherosclerosis. Consistently, deficiency in myeloid cells of either the enzyme arginase 1 (Arg1), which converts arginine to ornithine, or the enzyme ornithine decarboxylase (ODC), which mediates the decarboxylation of ornithine to putrescine (Figure 2), is associated with efferocytic dysfunction and defective atherosclerosis resolution (105).

Several lines of evidence support also an important role of mitochondrial metabolism on the modulation of efferocytosis and efferocytosis-dependent resolution of inflammation. Metabolomic analysis of macrophages that have engulfed apoptotic material revealed metabolic reprograming of efferocytic macrophages toward fatty acid oxidation. Specifically, upregulation of pro-resolving IL-10 in efferocytic macrophages was mediated by mitochondrial beta-oxidation and induction of sirtuin1 signaling (18) (Figure 2). The interplay between mitochondrial activity and effective efferocytosis was also illustrated by analyzing the function of mitochondrial uncoupling protein 2 (Ucp2). Besides its function in uncoupling oxidative phosphorylation from synthesis of ATP, Ucp2 can promote efferocytosis by reducing the mitochondrial membrane potential of macrophages. In the same vein, deficiency of Ucp 2 resulted in defective apoptotic cell removal and was associated with development of atherosclerosis, whereas overexpression of Ucp2 enhanced efferocytosis (19). Additionally, dynamic alterations in mitochondrial physiology may dictate the outcome of efferocytosis. In particular, a major component of mitochondrial homeostasis, mitochondrial fission, mediated by the function of the GTPase dynamin-related protein 1 (Drp1), positively regulates continuous apoptotic cell removal by macrophages. Accordingly, the absence of Drp1 was associated with higher atherosclerosis development in low-density lipoprotein receptor 1 (Ldlr1) deficient mice (106).

Lipids deriving from the apoptotic cargo are abundant postengulfment digestion products (17); lipid metabolism induces activation of the nuclear receptors peroxisome proliferatoractivated receptor (PPAR) gamma and delta, LXR alpha and beta and retinoid $\times$ receptor $(\mathrm{RXR})$ alpha and beta (107) in macrophages (Figure 2). Activation of these transcription factors promotes upregulation of phagocytic receptors and bridging molecules and the resolving macrophage phenotype. For instance, TGF $\beta$ and IL-10, which both promote inflammation resolution, are upregulated in efferocytic macrophages in an LXRand PPAR delta-dependent manner (108, 109). Importantly, deficiency of these nuclear receptors has been linked to defective efferocytosis and development of chronic inflammation or autoimmune manifestations (108, 109). Moreover, LXR activation is involved in DEL-1-dependent efferocytosis and macrophage reprograming to a proresolving phenotype (41).
LXR signaling also regulates expression of transglutaminase 2 (Tgm2) (110), which acts as a co-receptor to $\alpha v \beta 3$-integrin and promotes formation of engulfing portals (111).

Cholesterol metabolism has been also implicated in the modulation of efferocytosis. Treatment of macrophages with the cholesterol-lowering drug lovastatin, which inhibits the rate-limiting enzyme of cholesterol synthesis 3-hydroxyl-3methylglutaryl coenzyme A (HMG-CoA) reductase, leads to increased apoptotic cell clearance (112). Administration of another HMG-CoA reductase inhibitor, simvastatin, enhances the efferocytosis-dependent amelioration of inflammation in the context of lung fibrosis (113). Along the same line, the ATP-binding cassette transporter (ABCA1), a protein that modulates cholesterol efflux, is upregulated during efferocytosis in a manner dependent on LXR signaling (114). Furthermore, decreased hydrolysis of cholesterol esters and impaired oxysterol production, due to blockade of the enzyme lysosomal acid lipase, negatively affect LXR pathway activation and apoptotic cell removal, resulting in chronic inflammation (115). These studies point to the intimate crosstalk between cholesterol metabolism and nuclear receptor signaling involved in efferocytosis.

\section{CONCLUDING REMARKS}

Macrophage efferocytosis is a major player in resolution of inflammation. Efferocytosis not only paves the way toward the timely termination of the inflammatory response, but also promotes restoration of tissue homeostasis. In this context, alterations in macrophage cellular metabolism are important regulators of efferocytosis. At the same time, metabolic reprograming in efferocytic macrophages induced by digested apoptotic material substantially regulates the function and plasticity of efferocytic macrophages. Given the relevance of efferocytosis as a mechanism against chronic inflammatory disease, a better mechanistic understanding of the pathways that orchestrate the mutual interaction between clearance of dying cells and metabolic alterations in macrophages is required. This knowledge will provide a scaffold for designing therapeutic approaches to improve macrophage function in inflammation resolution and harness macrophage efferocytosis for the treatment of pathologies associated with chronic inflammation or autoimmunity.

\section{AUTHOR CONTRIBUTIONS}

IK, GH, and TC wrote the manuscript.

\section{FUNDING}

The authors were supported by grants from the National Institutes of Health (DE024716 to GH, DE028561 and DE026152 to GH and TC), the ERC (DEMETINL to TC), and the Deutsche Forschungsgemeinschaft (SFB1181 to TC). 


\section{REFERENCES}

1. Rosales C, Uribe-Querol E. Phagocytosis: a fundamental process in immunity. Biomed Res Int. (2017) 2017:9042851. doi: 10.1155/2017/9042851

2. Stuart LM, Ezekowitz RA. Phagocytosis: elegant complexity. Immunity. (2005) 22:539-50. doi: 10.1016/j.immuni.2005.05.002

3. Ortega-Gomez A, Perretti M, Soehnlein O. Resolution of inflammation: an integrated view. $E M B O \mathrm{Mol} \mathrm{Med}$. (2013) 5:661-74. doi: 10.1002/emmm. 201202382

4. Hajishengallis G, Chavakis T, Hajishengallis E, Lambris JD. Neutrophil homeostasis and inflammation: novel paradigms from studying periodontitis. J Leukoc Biol. (2015) 98:539-48. doi: 10.1189/jlb.3VMR1014$468 \mathrm{R}$

5. Soehnlein O, Steffens S, Hidalgo A, Weber C. Neutrophils as protagonists and targets in chronic inflammation. Nat Rev Immunol. (2017) 17:248-61. doi: $10.1038 /$ nri.2017.10

6. Ley K, Hoffman HM, Kubes P, Cassatella MA, Zychlinsky A, Hedrick CC, et al. Neutrophils: new insights and open questions. Sci Immunol. (2018) 3:eaat4579. doi: 10.1126/sciimmunol.aat 4579

7. Doran AC, Yurdagul A Jr., Tabas I. Efferocytosis in health and disease. Nat Rev Immunol. (2019). doi: 10.1038/s41577-019-0240-6 [Epub ahead of print].

8. Kourtzelis I, Mitroulis I, von Renesse J, Hajishengallis G, Chavakis T. From leukocyte recruitment to resolution of inflammation: the cardinal role of integrins. J Leukoc Biol. (2017) 102:677-83. doi: 10.1189/jlb.3MR0117-024R

9. Serhan CN, Levy BD. Resolvins in inflammation: emergence of the proresolving superfamily of mediators. J Clin Invest. (2018) 128:2657-69. doi: 10.1172/JCI97943

10. Headland SE, Norling LV. The resolution of inflammation: principles and challenges. Semin Immunol. (2015) 27:149-60. doi: 10.1016/j.smim.2015.03. 014

11. Ravichandran KS. Find-me and eat-me signals in apoptotic cell clearance: progress and conundrums. J Exp Med. (2010) 207:1807-17. doi: 10.1084/jem. 20101157

12. Serhan CN, Chiang N, Dalli J, Levy BD. Lipid mediators in the resolution of inflammation. Cold Spring Harb Perspect Biol. (2014) 7:a016311. doi: 10. 1101/cshperspect.a016311

13. Fond AM, Ravichandran KS. Clearance of dying cells by phagocytes: mechanisms and implications for disease pathogenesis. Adv Exp Med Biol. (2016) 930:25-49. doi: 10.1007/978-3-319-39406-0_2

14. Thorp E, Tabas I. Mechanisms and consequences of efferocytosis in advanced atherosclerosis. J Leukoc Biol. (2009) 86:1089-95. doi: 10.1189/jlb.0209115

15. Kawano M, Nagata S. Efferocytosis and autoimmune disease. Int Immunol. (2018) 30:551-8. doi: 10.1093/intimm/dxy055

16. O’Neill LA, Pearce EJ. Immunometabolism governs dendritic cell and macrophage function. J Exp Med. (2016) 213:15-23. doi: 10.1084/jem. 20151570

17. Stunault MI, Bories G, Guinamard RR, Ivanov S. Metabolism plays a key role during macrophage activation. Mediators Inflamm. (2018) 2018:2426138. doi: $10.1155 / 2018 / 2426138$

18. Zhang S, Weinberg S, DeBerge M, Gainullina A, Schipma M, Kinchen JM, et al. Efferocytosis fuels requirements of fatty acid oxidation and the electron transport chain to polarize macrophages for tissue repair. Cell Metab. (2019) 29:443-56.e5. doi: 10.1016/j.cmet.2018.12.004

19. Park D, Han CZ, Elliott MR, Kinchen JM, Trampont PC, Das S, et al. Continued clearance of apoptotic cells critically depends on the phagocyte Ucp2 protein. Nature. (2011) 477:220-4. doi: 10.1038/nature10340

20. Park SY, Kim IS. Engulfment signals and the phagocytic machinery for apoptotic cell clearance. Exp Mol Med. (2017) 49:e331. doi: 10.1038/emm. 2017.52

21. Medina CB, Ravichandran KS. Do not let death do us part: 'find-me' signals in communication between dying cells and the phagocytes. Cell Death Differ. (2016) 23:979-89. doi: 10.1038/cdd.2016.13

22. Elliott MR, Chekeni FB, Trampont PC, Lazarowski ER, Kadl A, Walk SF, et al. Nucleotides released by apoptotic cells act as a find-me signal to promote phagocytic clearance. Nature. (2009) 461:282-6. doi: 10.1038/nature 08296
23. Lauber K, Bohn E, Krober SM, Xiao YJ, Blumenthal SG, Lindemann RK, et al. Apoptotic cells induce migration of phagocytes via caspase-3-mediated release of a lipid attraction signal. Cell. (2003) 113:717-30. doi: 10.1016/ s0092-8674(03)00422-7

24. Gude DR, Alvarez SE, Paugh SW, Mitra P, Yu J, Griffiths R, et al. Apoptosis induces expression of sphingosine kinase 1 to release sphingosine1-phosphate as a "come-and-get-me" signal. FASEB J. (2008) 22:2629-38. doi: 10.1096/fj.08-107169

25. Moffatt OD, Devitt A, Bell ED, Simmons DL, Gregory CD. Macrophage recognition of ICAM-3 on apoptotic leukocytes. J Immunol. (1999) $162: 6800-10$

26. Savill J, Hogg N, Ren Y, Haslett C. Thrombospondin cooperates with CD36 and the vitronectin receptor in macrophage recognition of neutrophils undergoing apoptosis. J Clin Invest. (1992) 90:1513-22. doi: 10.1172/ JCI116019

27. Elliott MR, Ravichandran KS. The dynamics of apoptotic cell clearance. Dev Cell. (2016) 38:147-60. doi: 10.1016/j.devcel.2016.06.029

28. Poon IK, Lucas CD, Rossi AG, Ravichandran KS. Apoptotic cell clearance: basic biology and therapeutic potential. Nat Rev Immunol. (2014) 14:166-80. doi: $10.1038 /$ nri3607

29. Gardai SJ, McPhillips KA, Frasch SC, Janssen WJ, Starefeldt A, MurphyUllrich JE, et al. Cell-surface calreticulin initiates clearance of viable or apoptotic cells through trans-activation of LRP on the phagocyte. Cell. (2005) 123:321-34. doi: 10.1016/j.cell.2005.08.032

30. Jaillon S, Jeannin P, Hamon Y, Fremaux I, Doni A, Bottazzi B, et al. Endogenous PTX3 translocates at the membrane of late apoptotic human neutrophils and is involved in their engulfment by macrophages. Cell Death Differ. (2009) 16:465-74. doi: 10.1038/cdd.2008.173

31. Hanayama R, Tanaka M, Miyasaka K, Aozasa K, Koike M, Uchiyama Y, et al. Autoimmune disease and impaired uptake of apoptotic cells in MFG-E8deficient mice. Science. (2004) 304:1147-50. doi: 10.1126/science.1094359

32. Hanayama R, Tanaka M, Miwa K, Shinohara A, Iwamatsu A, Nagata S. Identification of a factor that links apoptotic cells to phagocytes. Nature. (2002) 417:182-7. doi: 10.1038/417182a

33. Hajishengallis G, Chavakis T. DEL-1-regulated immune plasticity and inflammatory disorders. Trends Mol Med. (2019) 25:444-59. doi: 10.1016/j. molmed.2019.02.010

34. Choi EY, Chavakis E, Czabanka MA, Langer HF, Fraemohs L, Economopoulou $M$, et al. Del-1, an endogenous leukocyte-endothelial adhesion inhibitor, limits inflammatory cell recruitment. Science. (2008) 322:1101-4. doi: 10.1126/science.1165218

35. Kourtzelis I, Kotlabova K, Lim JH, Mitroulis I, Ferreira A, Chen LS, et al. Developmental endothelial locus-1 modulates platelet-monocyte interactions and instant blood-mediated inflammatory reaction in islet transplantation. Thromb Haemost. (2016) 115:781-8. doi: 10.1160/TH15-05-0429

36. Mitroulis I, Alexaki VI, Kourtzelis I, Ziogas A, Hajishengallis G, Chavakis T. Leukocyte integrins: role in leukocyte recruitment and as therapeutic targets in inflammatory disease. Pharmacol Ther. (2015) 147:123-35. doi: 10.1016/j. pharmthera.2014.11.008

37. Hajishengallis G, Chavakis T. Endogenous modulators of inflammatory cell recruitment. Trends Immunol. (2013) 34:1-6. doi: 10.1016/j.it.2012.08.003

38. Shin J, Maekawa T, Abe T, Hajishengallis E, Hosur K, Pyaram K, et al. DEL-1 restrains osteoclastogenesis and inhibits inflammatory bone loss in nonhuman primates. Sci Transl Med. (2015) 7:307ra155. doi: 10.1126/ scitranslmed.aac5380

39. Chavakis T, Mitroulis I, Hajishengallis G. Hematopoietic progenitor cells as integrative hubs for adaptation to and fine-tuning of inflammation. Nat Immunol. (2019) 20:802-11. doi: 10.1038/s41590-019-0402-5

40. Mitroulis I, Chen LS, Singh RP, Kourtzelis I, Economopoulou M, Kajikawa T, et al. Secreted protein Del-1 regulates myelopoiesis in the hematopoietic stem cell niche. J Clin Invest. (2017) 127:3624-39. doi: 10.1172/JCI92571

41. Kourtzelis I, Li X, Mitroulis I, Grosser D, Kajikawa T, Wang B, et al. DEL1 promotes macrophage efferocytosis and clearance of inflammation. Nat Immunol. (2019) 20:40-9. doi: 10.1038/s41590-018-0249-1

42. Savill J, Dransfield I, Hogg N, Haslett C. Vitronectin receptor-mediated phagocytosis of cells undergoing apoptosis. Nature. (1990) 343:170-3. doi: $10.1038 / 343170 \mathrm{a} 0$ 
43. Hanayama R, Tanaka M, Miwa K, Nagata S. Expression of developmental endothelial locus-1 in a subset of macrophages for engulfment of apoptotic cells. J Immunol. (2004) 172:3876-82. doi: 10.4049/jimmunol.172.6.3876

44. Arur S, Uche UE, Rezaul K, Fong M, Scranton V, Cowan AE, et al. Annexin $\mathrm{I}$ is an endogenous ligand that mediates apoptotic cell engulfment. Dev Cell. (2003) 4:587-98. doi: 10.1016/s1534-5807(03)00090-x

45. Balasubramanian K, Schroit AJ. Characterization of phosphatidylserinedependent beta2-glycoprotein I macrophage interactions. Implications for apoptotic cell clearance by phagocytes. J Biol Chem. (1998) 273:29272-7. doi: $10.1074 /$ jbc.273.44.29272

46. Caberoy NB, Alvarado G, Bigcas JL, Li W. Galectin-3 is a new MerTK-specific eat-me signal. J Cell Physiol. (2012) 227:401-7. doi: 10.1002/jcp.22955

47. Anderson HA, Maylock CA, Williams JA, Paweletz CP, Shu H, Shacter E. Serum-derived protein $\mathrm{S}$ binds to phosphatidylserine and stimulates the phagocytosis of apoptotic cells. Nat Immunol. (2003) 4:87-91. doi: 10.1038/ ni871

48. Lemke G, Burstyn-Cohen T. TAM receptors and the clearance of apoptotic cells. Ann N Y Acad Sci. (2010) 1209:23-9. doi: 10.1111/j.1749-6632.2010. 05744.x

49. Scott RS, McMahon EJ, Pop SM, Reap EA, Caricchio R, Cohen PL, et al. Phagocytosis and clearance of apoptotic cells is mediated by MER. Nature. (2001) 411:207-11. doi: 10.1038/35075603

50. Rothlin CV, Ghosh S, Zuniga EI, Oldstone MB, Lemke G. TAM receptors are pleiotropic inhibitors of the innate immune response. Cell. (2007) 131:112436. doi: 10.1016/j.cell.2007.10.034

51. Lemke G, Rothlin CV. Immunobiology of the TAM receptors. Nat Rev Immunol. (2008) 8:327-36. doi: 10.1038/nri2303

52. Lumbroso D, Soboh S, Maimon A, Schif-Zuck S, Ariel A, Burstyn-Cohen T. Macrophage-derived protein $S$ facilitates apoptotic polymorphonuclear cell clearance by resolution phase macrophages and supports their reprogramming. Front Immunol. (2018) 9:358. doi: 10.3389/fimmu.2018. 00358

53. Miyanishi M, Tada K, Koike M, Uchiyama Y, Kitamura T, Nagata S. Identification of Tim4 as a phosphatidylserine receptor. Nature. (2007) 450:435-9. doi: 10.1038/nature06307

54. Kobayashi N, Karisola P, Pena-Cruz V, Dorfman DM, Jinushi M, Umetsu SE, et al. TIM-1 and TIM-4 glycoproteins bind phosphatidylserine and mediate uptake of apoptotic cells. Immunity. (2007) 27:927-40. doi: 10.1016/ j.immuni.2007.11.011

55. Park D, Tosello-Trampont AC, Elliott MR, Lu M, Haney LB, Ma Z, et al. BAI1 is an engulfment receptor for apoptotic cells upstream of the ELMO/Dock180/Rac module. Nature. (2007) 450:430-4. doi: 10.1038/ nature06329

56. Park SY, Jung MY, Kim HJ, Lee SJ, Kim SY, Lee BH, et al. Rapid cell corpse clearance by stabilin-2, a membrane phosphatidylserine receptor. Cell Death Differ. (2008) 15:192-201. doi: 10.1038/sj.cdd.4402242

57. Mevorach D, Mascarenhas JO, Gershov D, Elkon KB. Complementdependent clearance of apoptotic cells by human macrophages. J Exp Med. (1998) 188:2313-20. doi: 10.1084/jem.188.12.2313

58. Devitt A, Moffatt OD, Raykundalia C, Capra JD, Simmons DL, Gregory CD. Human CD14 mediates recognition and phagocytosis of apoptotic cells. Nature. (1998) 392:505-19. doi: 10.1038/33169

59. Oldenborg PA, Zheleznyak A, Fang YF, Lagenaur CF, Gresham HD, Lindberg FP. Role of CD47 as a marker of self on red blood cells. Science. (2000) 288:2051-4. doi: 10.1126/science.288.5473.2051

60. Oldenborg PA, Gresham HD, Lindberg FP. CD47-signal regulatory protein alpha (SIRPalpha) regulates Fcgamma and complement receptor-mediated phagocytosis. J Exp Med. (2001) 193:855-62. doi: 10.1084/jem.193.7.855

61. Kojima Y, Volkmer JP, McKenna K, Civelek M, Lusis AJ, Miller CL, et al. CD47-blocking antibodies restore phagocytosis and prevent atherosclerosis. Nature. (2016) 536:86-90. doi: 10.1038/nature18935

62. Brown S, Heinisch I, Ross E, Shaw K, Buckley CD, Savill J. Apoptosis disables CD31-mediated cell detachment from phagocytes promoting binding and engulfment. Nature. (2002) 418:200-3. doi: 10.1038/nature00811

63. Barkal AA, Brewer RE, Markovic M, Kowarsky M, Barkal SA, Zaro BW, et al. CD24 signalling through macrophage Siglec-10 is a target for cancer immunotherapy. Nature. (2019) 572:392-6. doi: 10.1038/s41586-019-1456-0
64. Elward K, Griffiths M, Mizuno M, Harris CL, Neal JW, Morgan BP, et al. CD46 plays a key role in tailoring innate immune recognition of apoptotic and necrotic cells. J Biol Chem. (2005) 280:36342-54. doi: 10.1074/jbc. M506579200

65. Barth ND, Marwick JA, Vendrell M, Rossi AG, Dransfield I. The "Phagocytic Synapse" and clearance of apoptotic cells. Front Immunol. (2017) 8:1708. doi: 10.3389/fimmu.2017.01708

66. Kinchen JM, Ravichandran KS. Phagocytic signaling: you can touch, but you can't eat. Curr Biol. (2008) 18:R521-4. doi: 10.1016/j.cub.2008.04.058

67. Ariel A, Serhan CN. New lives given by cell death: macrophage differentiation following their encounter with apoptotic leukocytes during the resolution of inflammation. Front Immunol. (2012) 3:4. doi: 10.3389/fimmu.2012.00004

68. Bratton DL, Henson PM. Neutrophil clearance: when the party is over, clean-up begins. Trends Immunol. (2011) 32:350-7. doi: 10.1016/j.it.2011.04. 009

69. Henson PM. Cell removal: efferocytosis. Annu Rev Cell Dev Biol. (2017) 33:127-44. doi: 10.1146/annurev-cellbio-111315-125315

70. Henson PM, Bratton DL. Antiinflammatory effects of apoptotic cells. J Clin Invest. (2013) 123:2773-4. doi: 10.1172/JCI69344

71. Sugimoto MA, Vago JP, Perretti M, Teixeira MM. Mediators of the resolution of the inflammatory response. Trends Immunol. (2019) 40:212-27. doi: 10. 1016/j.it.2019.01.007

72. Fadok VA, Bratton DL, Konowal A, Freed PW, Westcott JY, Henson PM. Macrophages that have ingested apoptotic cells in vitro inhibit proinflammatory cytokine production through autocrine/paracrine mechanisms involving TGF-beta, PGE2, and PAF. J Clin Invest. (1998) 101:890-8. doi: 10.1172/JCI1112

73. Huynh ML, Fadok VA, Henson PM. Phosphatidylserine-dependent ingestion of apoptotic cells promotes TGF-betal secretion and the resolution of inflammation. J Clin Invest. (2002) 109:41-50. doi: 10.1172/ JCI11638

74. Proto JD, Doran AC, Gusarova G, Yurdagul A Jr., Sozen E, Subramanian $\mathrm{M}$, et al. Regulatory $\mathrm{T}$ cells promote macrophage efferocytosis during inflammation resolution. Immunity. (2018) 49:666-77.e6. doi: 10.1016/j. immuni.2018.07.015

75. Schauer C, Janko C, Munoz LE, Zhao Y, Kienhofer D, Frey B, et al. Aggregated neutrophil extracellular traps limit inflammation by degrading cytokines and chemokines. Nat Med. (2014) 20:511-7. doi: 10.1038/nm.3547

76. Levy BD, Clish CB, Schmidt B, Gronert K, Serhan CN. Lipid mediator class switching during acute inflammation: signals in resolution. Nat Immunol. (2001) 2:612-9. doi: 10.1038/89759

77. Uderhardt S, Herrmann M, Oskolkova OV, Aschermann S, Bicker W, Ipseiz $\mathrm{N}$, et al. 12/15-lipoxygenase orchestrates the clearance of apoptotic cells and maintains immunologic tolerance. Immunity. (2012) 36:834-46. doi: 10.1016/j.immuni.2012.03.010

78. Stables MJ, Shah S, Camon EB, Lovering RC, Newson J, Bystrom J, et al. Transcriptomic analyses of murine resolution-phase macrophages. Blood. (2011) 118:e192-208. doi: 10.1182/blood-2011-04-345330

79. Kumaran Satyanarayanan S, El Kebir D, Soboh S, Butenko S, Sekheri M, Saadi J, et al. IFN-beta is a macrophage-derived effector cytokine facilitating the resolution of bacterial inflammation. Nat Commun. (2019) 10:3471. doi: 10.1038/s41467-019-10903-9

80. Schif-Zuck S, Gross N, Assi S, Rostoker R, Serhan CN, Ariel A. Saturatedefferocytosis generates pro-resolving CD11b low macrophages: modulation by resolvins and glucocorticoids. Eur J Immunol. (2011) 41:366-79. doi: 10.1002/eji.201040801

81. Freire-de-Lima CG, Xiao YQ, Gardai SJ, Bratton DL, Schiemann WP, Henson PM. Apoptotic cells, through transforming growth factor-beta, coordinately induce anti-inflammatory and suppress pro-inflammatory eicosanoid and NO synthesis in murine macrophages. J Biol Chem. (2006) 281:38376-84. doi: 10.1074/jbc.M605146200

82. Sugimoto MA, Ribeiro ALC, Costa BRC, Vago JP, Lima KM, Carneiro FS, et al. Plasmin and plasminogen induce macrophage reprogramming and regulate key steps of inflammation resolution via annexin A1. Blood. (2017) 129:2896-907. doi: 10.1182/blood-2016-09-742825

83. Vago JP, Sugimoto MA, Lima KM, Negreiros-Lima GL, Baik N, Teixeira $\mathrm{MM}$, et al. Plasminogen and the plasminogen receptor, Plg-RKT, regulate 
macrophage phenotypic, and functional changes. Front Immunol. (2019) 10:1458. doi: 10.3389/fimmu.2019.01458

84. Sousa LP, Alessandri AL, Pinho V, Teixeira MM. Pharmacological strategies to resolve acute inflammation. Curr Opin Pharmacol. (2013) 13:625-31. doi: 10.1016/j.coph.2013.03.007

85. Sugimoto MA, Vago JP, Teixeira MM, Sousa LP. Annexin Al and the resolution of inflammation: modulation of neutrophil recruitment, apoptosis, and clearance. J Immunol Res. (2016) 2016:8239258. doi: 10.1155/ 2016/8239258

86. Galvao I, Vago JP, Barroso LC, Tavares LP, Queiroz-Junior CM, Costa VV, et al. Annexin A1 promotes timely resolution of inflammation in murine gout. Eur J Immunol. (2017) 47:585-96. doi: 10.1002/eji.201646551

87. Souza DG, Fagundes CT, Amaral FA, Cisalpino D, Sousa LP, Vieira AT, et al. The required role of endogenously produced lipoxin A4 and annexin- 1 for the production of IL-10 and inflammatory hyporesponsiveness in mice. $J$ Immunol. (2007) 179:8533-43. doi: 10.4049/jimmunol.179.12.8533

88. Vago JP, Nogueira CR, Tavares LP, Soriani FM, Lopes F, Russo RC, et al. Annexin A1 modulates natural and glucocorticoid-induced resolution of inflammation by enhancing neutrophil apoptosis. J Leukoc Biol. (2012) 92:249-58. doi: 10.1189/jlb.0112008

89. O’Neill LA, Kishton RJ, Rathmell J. A guide to immunometabolism for immunologists. Nat Rev Immunol. (2016) 16:553-65. doi: 10.1038/nri.2016. 70

90. Pearce EL, Pearce EJ. Metabolic pathways in immune cell activation and quiescence. Immunity. (2013) 38:633-43. doi: 10.1016/j.immuni.2013.04.005

91. Van den Bossche J, O'Neill LA, Menon D. Macrophage immunometabolism: where are we (going)? Trends Immunol. (2017) 38:395-406. doi: 10.1016/j.it. 2017.03.001

92. Diskin C, Palsson-McDermott EM. Metabolic modulation in macrophage effector function. Front Immunol. (2018) 9:270. doi: 10.3389/fimmu.2018. 00270

93. Rosas M, Davies LC, Giles PJ, Liao CT, Kharfan B, Stone TC, et al. The transcription factor Gata6 links tissue macrophage phenotype and proliferative renewal. Science. (2014) 344:645-8. doi: 10.1126/science. 1251414

94. Okabe Y, Medzhitov R. Tissue-specific signals control reversible program of localization and functional polarization of macrophages. Cell. (2014) 157:832-44. doi: 10.1016/j.cell.2014.04.016

95. A-Gonzalez N, Guillen JA, Gallardo G, Diaz M, de la Rosa JV, Hernandez IH, et al. The nuclear receptor LXRalpha controls the functional specialization of splenic macrophages. Nat Immunol. (2013) 14:831-9. doi: 10.1038/ ni.2622

96. Davies LC, Taylor PR. Tissue-resident macrophages: then and now. Immunology. (2015) 144:541-8. doi: 10.1111/imm.12451

97. Gautier EL, Shay T, Miller J, Greter M, Jakubzick C, Ivanov S, et al. Geneexpression profiles and transcriptional regulatory pathways that underlie the identity and diversity of mouse tissue macrophages. Nat Immunol. (2012) 13:1118-28. doi: 10.1038/ni.2419

98. A-Gonzalez N, Quintana JA, Garcia-Silva S, Mazariegos M, Gonzalez de la Aleja A, Nicolas-Avila JA, et al. Phagocytosis imprints heterogeneity in tissueresident macrophages. J Exp Med. (2017) 214:1281-96. doi: 10.1084/jem. 20161375

99. Han CZ, Ravichandran KS. Metabolic connections during apoptotic cell engulfment. Cell. (2011) 147:1442-5. doi: 10.1016/j.cell.2011.12.006

100. Hochreiter-Hufford A, Ravichandran KS. Clearing the dead: apoptotic cell sensing, recognition, engulfment, and digestion. Cold Spring Harb Perspect Biol. (2013) 5:a008748. doi: 10.1101/cshperspect.a008748

101. Green DR, Oguin TH, Martinez J. The clearance of dying cells: table for two. Cell Death Differ. (2016) 23:915-26. doi: 10.1038/cdd.2015.172

102. Morioka S, Perry JSA, Raymond MH, Medina CB, Zhu Y, Zhao L, et al. Efferocytosis induces a novel SLC program to promote glucose uptake and lactate release. Nature. (2018) 563:714-8. doi: 10.1038/s41586-018-0735-5
103. Freemerman AJ, Zhao L, Pingili AK, Teng B, Cozzo AJ, Fuller AM, et al. Myeloid Slc2a1-deficient murine model revealed macrophage activation and metabolic phenotype are fueled by GLUT1. J Immunol. (2019) 202:1265-86. doi: 10.4049/jimmunol.1800002

104. Jiang $\mathrm{H}$, Shi H, Sun M, Wang $\mathrm{Y}$, Meng Q, Guo P, et al. PFKFB3-driven macrophage glycolytic metabolism is a crucial component of innate antiviral defense. J Immunol. (2016) 197:2880-90. doi: 10.4049/jimmunol.1600474

105. Yurdagul A Jr., Subramanian M, Wang X, Crown SB, Ilkayeva OR, Darville $\mathrm{L}$, et al. Macrophage metabolism of apoptotic cell-derived arginine promotes continual efferocytosis and resolution of injury. Cell Metab. (2020) 31:51833.e10. doi: 10.1016/j.cmet.2020.01.001

106. Wang Y, Subramanian M, Yurdagul A Jr., Barbosa-Lorenzi VC, Cai B, de Juan-Sanz J, et al. Mitochondrial fission promotes the continued clearance of apoptotic cells by macrophages. Cell. (2017) 171:331-45.e22. doi: 10.1016/ j.cell.2017.08.041

107. A-Gonzalez N, Hidalgo A. Nuclear receptors and clearance of apoptotic cells: stimulating the macrophage's appetite. Front Immunol. (2014) 5:211. doi: $10.3389 /$ fimmu.2014.00211

108. A-Gonzalez N, Bensinger SJ, Hong C, Beceiro S, Bradley MN, Zelcer N, et al. Apoptotic cells promote their own clearance and immune tolerance through activation of the nuclear receptor LXR. Immunity. (2009) 31:245-58. doi: 10.1016/j.immuni.2009.06.018

109. Mukundan L, Odegaard JI, Morel CR, Heredia JE, Mwangi JW, RicardoGonzalez RR, et al. PPAR-delta senses and orchestrates clearance of apoptotic cells to promote tolerance. Nat Med. (2009) 15:1266-72. doi: 10.1038/nm. 2048

110. Rebe C, Raveneau M, Chevriaux A, Lakomy D, Sberna AL, Costa A, et al. Induction of transglutaminase 2 by a liver $\mathrm{X}$ receptor/retinoic acid receptor alpha pathway increases the clearance of apoptotic cells by human macrophages. Circ Res. (2009) 105:393-401. doi: 10.1161/CIRCRESAHA.109. 201855

111. Toth B, Garabuczi E, Sarang Z, Vereb G, Vamosi G, Aeschlimann D, et al. Transglutaminase 2 is needed for the formation of an efficient phagocyte portal in macrophages engulfing apoptotic cells. J Immunol. (2009) 182:208492. doi: 10.4049/jimmunol.0803444

112. Morimoto K, Janssen WJ, Fessler MB, McPhillips KA, Borges VM, Bowler $\mathrm{RP}$, et al. Lovastatin enhances clearance of apoptotic cells (efferocytosis) with implications for chronic obstructive pulmonary disease. J Immunol. (2006) 176:7657-65. doi: 10.4049/jimmunol.176.12.7657

113. Lee YJ, Kim MJ, Yoon YS, Choi YH, Kim HS, Kang JL. Simvastatin treatment boosts benefits of apoptotic cell infusion in murine lung fibrosis. Cell Death Dis. (2017) 8:e2860. doi: 10.1038/cddis.2017.260

114. Venkateswaran A, Laffitte BA, Joseph SB, Mak PA, Wilpitz DC, Edwards PA, et al. Control of cellular cholesterol efflux by the nuclear oxysterol receptor LXR alpha. Proc Natl Acad Sci USA. (2000) 97:12097-102. doi: 10.1073/pnas. 200367697

115. Viaud M, Ivanov S, Vujic N, Duta-Mare M, Aira LE, Barouillet T, et al. Lysosomal cholesterol hydrolysis couples efferocytosis to antiinflammatory oxysterol production. Circ Res. (2018) 122:1369-84. doi: 10. 1161/CIRCRESAHA.117.312333

Conflict of Interest: The authors declare that the research was conducted in the absence of any commercial or financial relationships that could be construed as a potential conflict of interest.

Copyright $\odot 2020$ Kourtzelis, Hajishengallis and Chavakis. This is an open-access article distributed under the terms of the Creative Commons Attribution License (CC BY). The use, distribution or reproduction in other forums is permitted, provided the original author(s) and the copyright owner(s) are credited and that the original publication in this journal is cited, in accordance with accepted academic practice. No use, distribution or reproduction is permitted which does not comply with these terms. 